\title{
Melanoma Cells Constitutively Release an Anchor-positive Soluble Form of Protectin (sCD59) That Retains Functional Activities in Homologous Complement-mediated Cytotoxicity
}

\author{
Lorelei I. Brasoveanu, ${ }^{*}$ Ester Fonsatti, ${ }^{*}$ Alberto Visintin, ${ }^{\star}$ Mirjana Pavlovic, ${ }^{*}$ Ilaria Cattarossi, ${ }^{*}$ Francesca Colizzi, \\ Aldo Gasparollo, ${ }^{\star}$ Sandra Coral, ${ }^{\star}$ Vaclav Horejsi, ${ }^{\ddagger}$ Maresa Altomonte, ${ }^{*}$ and Michele Maio* \\ *Advanced Immunotherapy Unit, Istituto Nazionale di Ricovero e Cura a Carattere Scientifico, Centro di Riferimento Oncologico, \\ Aviano, Italy 33081; and ${ }^{\ddagger}$ Institute of Molecular Genetics, Prague, Czech Republic 14220
}

\begin{abstract}
Protectin (CD59), a glycosylphosphatidylinositol-anchored cell membrane glycoprotein, is differentially expressed on melanocytic cells and represents the main restriction factor of C-mediated lysis of melanoma cells. In this study, we report that CD59-positive melanoma cells constitutively release a soluble form of CD59 (sCD59), and that its levels directly correlate $(r=0.926 ; P<0.05)$ with the amount of membrane-bound CD59. SDS-PAGE analysis showed that the molecular components of sCD59 are similar to those of cellular CD59 expressed by melanoma cells. Melanomareleased sCD59 is anchor positive since it inserts into cell membranes of homologous cells that transiently increase their expression of CD59. Moreover, $\mathrm{sCD} 59$ is functional: it blocks the binding of the anti-CD59 mAb YTH53.1 to melanoma cells and reverses its effects on C-mediated lysis. In fact, preincubation of mAb YTH53.1 with scalar doses of conditioned media of CD59-positive but not of CD59-negative melanoma cells reduced significantly $(P<0.05)$, and in a dose-dependent fashion, the enhancement of $\mathrm{C}$-mediated lysis of anti-GD3-sensitized melanoma cells induced by the masking of cellular CD59 by mAb YTH53.1. Altogether, these data demonstrate that CD59-positive human melanoma cells release a soluble form of CD59 that is structurally similar to cellular CD59, retains its anchoring ability, is functional, and may impair the effectiveness of clinical approaches to humoral immunotherapy for human melanoma. (J. Clin. Invest. 1997. 100:1248-1255.) Key words: GPI anchor • PI-PLC • shedding • immunotherapy • malignant disease
\end{abstract}

\section{Introduction}

Normal and neoplastic cells are protected from autologous $\mathrm{C}$-mediated lysis by different cell membrane proteins that control discrete steps of C activation (1). Among these, CD59, previously described as H19, MEM-43, MIRL, MACIF,

Address correspondence to Dr. Michele Maio, Advanced Immunotherapy Unit, I.N.R.C.C.S.-C.R.O., Via Pedemontana Occ. le 12, Aviano, Italy 33081. Phone: 39-434-659342; FAX: 39-434-659566; E-mail: mmaio@ets.it

Received for publication 28 January 1997 and accepted in revised form 29 April 1997.

J. Clin. Invest.

(C) The American Society for Clinical Investigation, Inc. 0021-9738/97/09/1248/08 \$2.00

Volume 100, Number 5, September 1997, 1248-1255

http://www.jci.org
HRF20, and protectin (2), inhibits the cytolytic activity of homologous $\mathrm{C}$ by binding to $\mathrm{C} 8$ and $\mathrm{C} 9$ and blocking the assembly of the membrane-attack complex (3). CD59 is a broadly distributed $(4,5) 18-20-\mathrm{kD}$ cell membrane glycoprotein that is covalently attached to the lipid bilayer by a glycosylphosphatidylinositol anchor (6).

The expression of CD59 has been demonstrated on different normal tissues $(4,5)$ and, among neoplastic tissues, in malignant gliomas (7), breast (8), colon (9), lung, and renal (10) carcinomas. Moreover, large quantities of CD59 have been identified in tumor stroma compared to normal connective tissues (10). We have recently shown that CD59 is expressed differentially on normal and neoplastic cells of the melanocytic lineage in a totally glycosylphosphatidylinositol-anchored form, and that CD59 protects melanoma cells from homologous $\mathrm{C}$ attack $(11,12)$. In addition, we have demonstrated that CD59 is the main regulator of $\mathrm{C}$-mediated lysis of melanoma cells, and that the extent of lysis of anti-GD3-sensitized melanoma cells by homologous $\mathrm{C}$ correlates with levels of cell membrane expression of CD59 (12). Further studies by Junnikkala and colleagues (13) have suggested recently that CD59 expressed by melanoma cells may have therapeutic implications since it can be used to target the membrane-attack complex to antiGD3-sensitized melanoma cells without nonspecific lysis of bystander nonneoplastic cells.

A soluble form of CD59 (sCD59) ${ }^{1}$ has been found in different physiologic body fluids, including urine (4), amniotic fluid (14), seminal plasma (15), retroplacental sera, serum from umbilical cord blood and from blood of 0-12-mo-old children (16), colostrum/milk (16), and cerebrospinal fluid (17). However, only scattered data are available on the cellular sources of sCD59, and, to the best of our knowledge, no data are available on the release of sCD59 by malignant cells of different histotype $(4,5,7-10)$ or on its possible functional implications.

Human melanoma cells release different cell membrane molecules that regulate their interactions with host cellular and humoral immune systems. Among these, the release of intercellular adhesion molecule-1 (18), HLA class I and class II antigens (19), and GD3 gangliosides (20) has been well characterized. The shedding of cell membrane molecules by melanoma cells may contribute to their escape from constitutive and treatment-induced immune control in vivo (21-23) and

1. Abbreviations used in this paper: AP sCD59, immunoaffinity-purified soluble CD59; CM, conditioned media; DTAF, dichlorotriazynylaminofluorescein; HUVEC, human umbilical vein endothelial cells; IIF, indirect immunofluorescence; MESF, molecular equivalent of soluble fluorescein; NHS, normal human serum; PI-PLC, phosphatidylinositol-specific phospholipase C; RT, room temperature; sCD59, soluble CD59. 
may also impair therapeutic approaches based on active and/ or adoptive humoral and T cell-based immunotherapy of melanoma patients (24).

In this study, in light of the above considerations, the differential expression of CD59 by melanoma cells, and its functional role in protecting neoplastic cells of melanocytic lineage by homologous $\mathrm{C}$-mediated lysis, we investigated the presence, the molecular features, and the functional role of sCD59 in human melanoma.

\section{Methods}

$m A b s$, conventional antisera, and reagents. The anti-CD59 mAb MEM43 (mouse IgG2a) and MEM-43/5 (mouse IgG2b) were characterized as previously described (25). The anti-CD59 mAb YTH53.1 (rat IgG2b) (4) and the anti-GD3 ganglioside mAb R24 (mouse IgG3) (26) were kindly provided by Dr. Peter Lachmann (Department of Pathology, University of Cambridge, United Kingdom), and Dr. Alan Houghton (Memorial Sloan-Kettering Cancer Center, New York), respectively. mAbs were purified from ascitic fluid as described (27); the purity of $\mathrm{mAb}$ preparations was tested by SDS-PAGE analysis (28). mAbs were radiolabeled with ${ }^{125}$ I (Amersham International, Buckinghamshire, United Kingdom) by the chloramine T method (27). Dichlorotriazynylaminofluorescein (DTAF)-labeled $\mathrm{F}\left(\mathrm{ab}^{\prime}\right)_{2}$ fragments of goat anti-rat IgG antibodies, Fc fragment-specific, rabbit antimouse Ig antibodies, Fc fragment-specific, and ChromePure mouse and rat IgG were purchased from Jackson ImmunoResearch Laboratories, Inc. (West Grove, PA). R-phycoerythrin-conjugated $\mathrm{F}\left(\mathrm{ab}^{\prime}\right)_{2}$ fragments of rabbit anti-mouse IgG antibodies, Fc fragment-specific, were purchased from DAKO A/S (Glostrup, Denmark).

Phosphatidylinositol-specific phospholipase C (PI-PLC) from $B a$ cillus cereus was purchased from Sigma Chemical Co. (St. Louis, $\mathrm{MO})$. CNBr-Sepharose 4B was purchased from Pharmacia Diagnostics AB (Uppsala, Sweden).

Cells and sera. The human melanoma cell lines Mel 97, Mel 90, Mel 116, Mel 134, Mel 100, Colo 38, 70-W, MeM 50-10, and MeWo, and the pre-B leukemia cell line Nalm-6 were grown in RPMI 1640 medium (Flow Laboratories, Inc., McLean, VA) supplemented with $10 \%$ heat-inactivated FCS (Flow Laboratories, Inc.) and $2 \mathrm{mM} \mathrm{L-glutamine.}$ Human foreskin melanocytes and human umbilical vein endothelial cells (HUVEC) were generated as previously described $(11,29)$.

Sera collected from melanoma patients, adult healthy controls, and umbilical cord blood were aliquoted and stored at $-20^{\circ} \mathrm{C}$ until used as source of sCD59. Normal human sera (NHS) collected from healthy lab volunteers, were aliquoted and stored at $-80^{\circ} \mathrm{C}$ until used as source of $\mathrm{C}$.

Cell lysates and conditioned media (CM). Lysates of $10^{7}$ cells in a final volume of $1 \mathrm{ml}$ were obtained as described (11) and used as source of cellular CD59, or stored at $-80^{\circ} \mathrm{C}$ with no loss of biological activity over a 3-mo period.

CM were prepared by seeding cells $\left(5 \times 10^{6}\right)$ in $15 \mathrm{ml}$ RPMI 1640 medium in T75 flasks. After a 48-h incubation, cells and culture supernatants were harvested separately; cells were then counted, and culture supernatants were centrifuged for $30 \mathrm{~min}$ at $15,000 \mathrm{~g}$ to remove cell debris, filtered through a $0.2-\mu \mathrm{m}$ acetate filter, placed in dialysis membranes with a molecular weight cut-off of $6,000-8,000 \mathrm{D}$ (Spectrum Medical Industries, Inc., Houston, TX), concentrated with 15,000-20,000 molecular weight polyethyleneglycol (Sigma Chemical Co.), dialyzed against PBS, filtered through a $0.2-\mu \mathrm{m}$ acetate filter, adjusted with PBS so that $1 \mathrm{ml}$ of CM corresponded to culture supernatant recovered from $10^{7}$ cells, aliquoted, and used as source of sCD59, or stored at $-80^{\circ} \mathrm{C}$ with no loss of biological activity over a 3-mo period.

Serological assays. Indirect immunofluorescence (IIF) was performed as previously described (27). Results are expressed as mean values of fluorescence intensity on a logarithmic scale or, as molecular equivalent of soluble fluorescein (MESF) values. The latter were obtained as described (12). A sample was classified as positive when $>5 \%$ of the cells were stained by specific $\mathrm{mAb}$. Mean values of fluorescence intensity and MESF values obtained with isotype-matched mouse or rat Ig were $<10$ and 1,920, respectively, on all cell lines tested.

Purification of SCD59. sCD59 was purified by immunoaffinity chromatography from CM $(700 \mathrm{ml})$ of Mel 97 melanoma cells $(3.5 \times$ $10^{8}$ ) prepared as described above, concentrated to a final volume of $35 \mathrm{ml}$, and added to $0.02 \mathrm{M}$ sodium azide. $\mathrm{CM}$ was precleared on a 3-ml $\mathrm{CNBr}-\mathrm{Sepharose} 4 \mathrm{~B}$ column precoated with $10 \mathrm{mg}$ of an irrelevant mouse $\mathrm{mAb}$, loaded on a $3-\mathrm{ml} \mathrm{CNBr}-\mathrm{Sepharose} 4 \mathrm{~B}$ column precoated with $10 \mathrm{mg}$ of anti-CD59 mAb MEM-43, and recirculated at a flow rate of $7 \mathrm{ml} / \mathrm{h}$ for $48 \mathrm{~h}$. Affinity-bound sCD59 was eluted by $0.1 \mathrm{M}$ glycine- $\mathrm{NaOH}$ buffer, $\mathrm{pH} 11.5$, and the eluate was immediately neutralized with $1 \mathrm{M}$ Tris- $\mathrm{HCl}, \mathrm{pH}$ 6.5. Eluates were then concentrated and dialyzed as described above for $\mathrm{CM}$, filtered through $0.2-\mu \mathrm{m}$ acetate filters, aliquoted, and stored at $-80^{\circ} \mathrm{C}$ until use. All experimental procedures were carried out at $4^{\circ} \mathrm{C}$. Protein concentration in eluates was determined by the Lowry assay.

Insertion of immunoaffinity-purified sCD59 (AP sCD59) into homologous cell membranes. MeWo and 70-W melanoma cells $\left(10^{6}\right)$ were incubated with $300 \mu \mathrm{l}$ PBS containing AP sCD59 $(5 \mu \mathrm{g} / \mathrm{ml})$ in a water bath at $37^{\circ} \mathrm{C}$ with occasional gentle shaking. After a 2-h incubation, cells were washed twice with PBS and divided into two aliquots. The first aliquot was processed for IIF analysis of CD59 expression, while the second aliquot was washed twice and incubated in $300 \mu \mathrm{l}$ PBS without AP sCD59 for an additional $2 \mathrm{~h}$ at $37^{\circ} \mathrm{C}$, and then processed for IIF analysis of CD59 expression. Melanoma cells incubated under similar experimental conditions but in the absence of AP sCD59 were used as control, and showed no changes in their constitutive expression of CD59 (data not shown).

PI-PLC treatment. Melanoma cells $\left(10^{7}\right)$ were resuspended in $500 \mu$ l RPMI 1640 medium supplemented with $10 \%$ FCS and $2 \mathrm{mM}$ L-glutamine, and added with different concentrations of PI-PLC. After a 2-h incubation at $37^{\circ} \mathrm{C}$ in a water bath, with occasional gentle shaking, cell suspensions were spun at $300 \mathrm{~g}$, and cells and supernatants were harvested separately. Cells were then used to assess levels of cell surface CD59 by IIF, while supernatants were centrifuged for $10 \mathrm{~min}$ at $15,000 \mathrm{~g}$ to remove cell debris, filtered through a $0.2-\mu \mathrm{m}$ acetate filter, and immediately used as source of released CD59, or stored at $-80^{\circ} \mathrm{C}$ with no loss of biological activity over a 3-mo period.

Immunoprecipitation, SDS-PAGE, and Western blotting. Immunoprecipitation, SDS-PAGE, and Western blotting were performed as previously described (27) using cell lysates, CM, and AP sCD59 from Mel 97 melanoma cells and the anti-CD59 mAb MEM-43/5 bound to protein A-Sepharose CL-4B (Pharmacia Diagnostics), precoated with rabbit anti-mouse Ig antibodies, Fc fragment-specific. For Western blotting, immunoprecipitated components were size-fractionated by one-dimensional SDS-PAGE on $15 \%$ polyacrylamide slab gels under nonreducing conditions and electroblotted onto Hybond-C super transfer nitrocellulose membranes (Amersham International). Membranes were then saturated with PBS containing 5\% nonfat dry milk and $0.02 \%$ sodium azide (blocking buffer) for $12 \mathrm{~h}$ at $4^{\circ} \mathrm{C}$, incubated with $5 \times 10^{5} \mathrm{cpm} / \mathrm{ml}$ of ${ }^{125} \mathrm{I}$-labeled mAb YTH53.1 in blocking buffer for $2 \mathrm{~h}$ at room temperature (RT), washed three times with blocking buffer and once with PBS, dried, and processed for autoradiography using Kodak XAR-5 film (Eastman Kodak Co., Rochester, NY).

Dot blotting. Cell lysates, CM, supernatants of PI-PLC-treated melanoma cells, and sera were spotted under vacuum onto Hybond-C super transfer nitrocellulose membranes by a 96-well dot blot apparatus (Schleicher \& Schuell, Inc., Dassel, Germany); membranes were then processed as described above. Before autoradiography, spotbound radioactivity was measured by a MATRIX 96 Direct Beta Counter (Packard Instruments, Meriden, CT).

Inhibition of the binding of ${ }^{125}$ I-labeled mAb YTH53.1 to cells by $C M$. Serial dilutions of CM from Mel 97 and MeWo melanoma cells and from Nalm- 6 pre-B cells were incubated with $0.1 \mathrm{ml}$ of ${ }^{125} \mathrm{I}$-labeled 
anti-CD59 mAb YTH53.1 $\left(10^{6} \mathrm{cpm}\right)$ to a final volume of $0.9 \mathrm{ml}$, under continuous shaking. After a 2-h incubation at RT, $0.1 \mathrm{ml}$ of $\mathrm{Mel}$ 134 melanoma cells $\left(5 \times 10^{5}\right)$ was added, and test tubes were incubated for an additional $2 \mathrm{~h}$ at RT. After four washings with PBS containing $1 \%$ nonfat dry milk and $0.02 \%$ sodium azide, cell-bound radioactivity was measured by a gamma counter (COBRA II; Packard Instruments). $100 \%$ of the binding of ${ }^{125}$ I-labeled mAb YTH53.1 to cells was assessed by incubating melanoma cells under similar experimental conditions but in PBS containing $1 \%$ nonfat dry milk and $0.02 \%$ sodium azide instead of $\mathrm{CM}$.

C-mediated cytotoxicity assays. All the assays were performed in triplicate as described (11), with minor modifications. Briefly, ${ }^{51} \mathrm{Cr}$ labeled Mel 134 and MeWo melanoma cells $\left(3 \times 10^{4}\right)$ were resuspended in RPMI 1640 medium and incubated with $2.5 \mu \mathrm{g} / \mathrm{ml}$ antiGD3 mAb R24 and/or $2.5 \mu \mathrm{g} / \mathrm{ml}$ anti-CD59 mAb YTH53.1 in a final volume of $0.1 \mathrm{ml}$. For some experiments, $2.5 \mu \mathrm{g}$ mAb YTH53.1 was
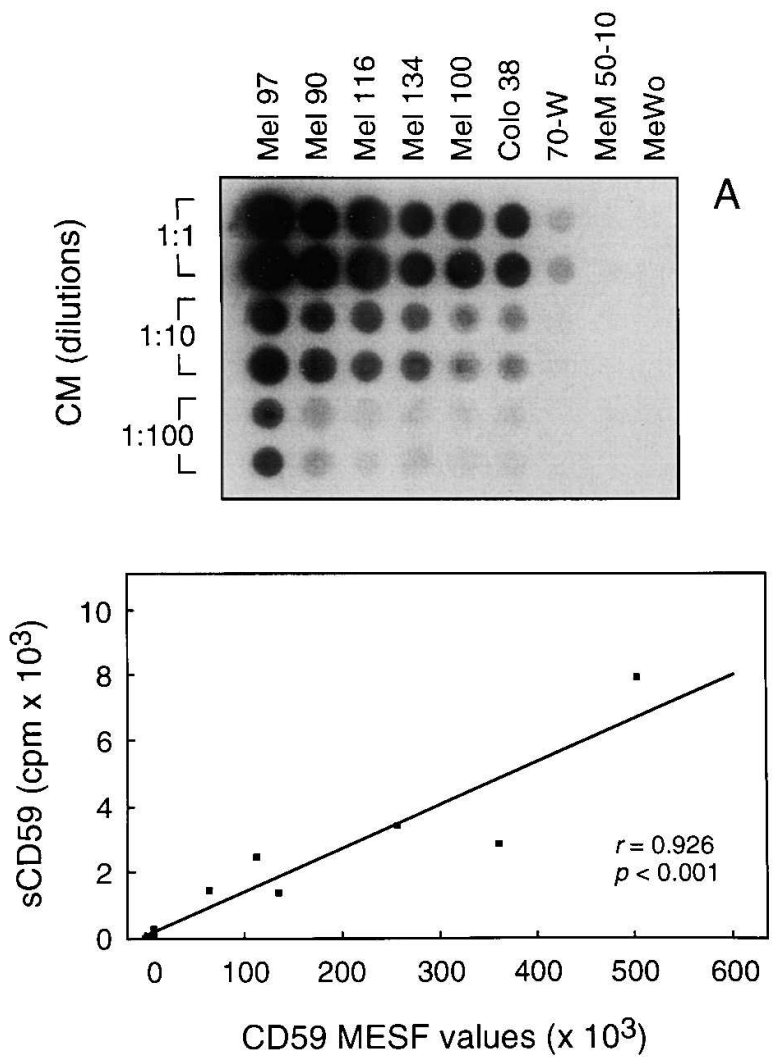

Figure 1. Dot blot analysis of sCD59 present in CM from different melanoma cells $(A)$ and correlation analysis with cell surface expression of CD59 (B). (A) 50- $\mu$ l serial dilutions of CM from Mel 97, Mel 90, Mel 116, Mel 134, Mel 100, Colo 38, 70-W, MeM 50-10, and MeWo melanoma cells were spotted under vacuum onto Hybond-C super transfer nitrocellulose membrane by a 96-well dot blot apparatus and incubated for $1 \mathrm{~h}$ at RT. After three washings with PBS/ $0.02 \%$ sodium azide, membranes were saturated with PBS containing $5 \%$ nonfat dry milk and $0.02 \%$ sodium azide (blocking buffer) for $12 \mathrm{~h}$ at $4^{\circ} \mathrm{C}$, then incubated with $50 \mathrm{ml}$ blocking buffer containing $5 \times$ $10^{5} \mathrm{cpm} / \mathrm{ml}$ of ${ }^{125} \mathrm{I}-\mathrm{mAb}$ YTH53.1 for $2 \mathrm{~h}$ at RT. Before autoradiography, spot-bound radioactivity was measured by a MATRIX 96 Direct Beta Counter. $(B)$ Melanoma cells $\left(10^{5}\right)$ were incubated sequentially with $10 \mu \mathrm{g} / \mathrm{ml}$ anti-CD59 mAb YTH53.1 and with DTAF-conjugated $\mathrm{F}\left(\mathrm{ab}^{\prime}\right)_{2}$ fragments of goat anti-rat IgG xenoantibodies; cells were then analyzed with flow cytometry. Levels of CD59, expressed as MESF values, were correlated by linear regression analysis with cpm values of spot-bound ${ }^{125} \mathrm{I}-\mathrm{mAb}$ YTH53.1.
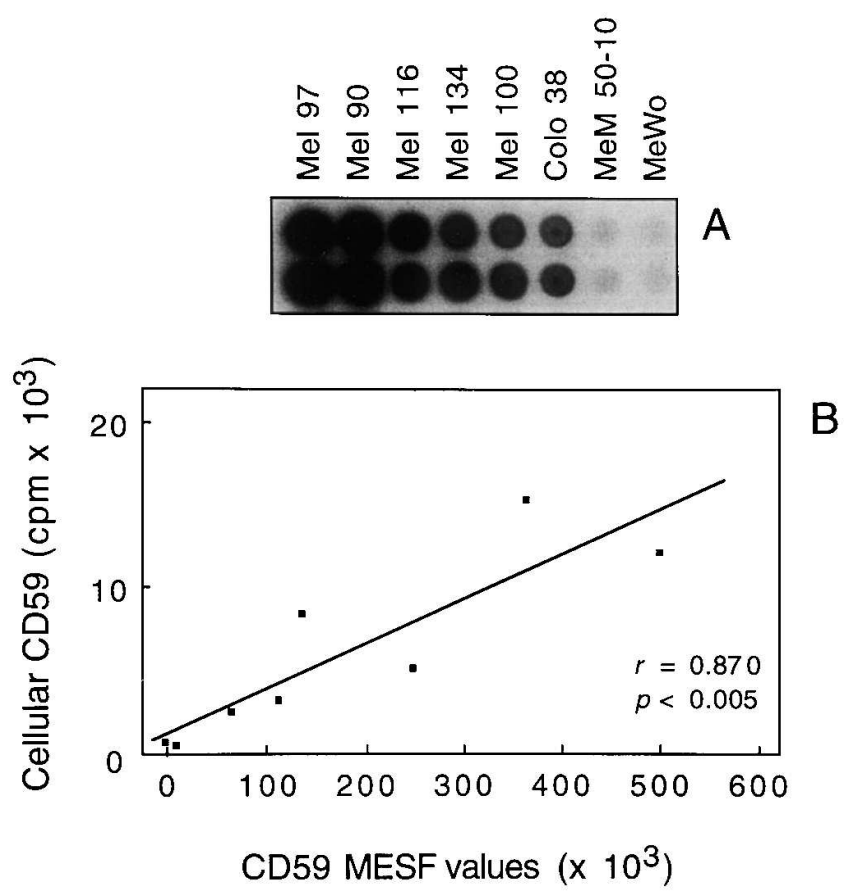

Figure 2. Dot blot analysis of cellular CD59 from different melanoma cells $(A)$ and correlation analysis with cell surface expression of CD59 (B). (A) 50- $\mu$ l cell lysates of Mel 97, Mel 90, Mel 116, Mel 134, Mel 100, Colo 38, MeM 50-10, and MeWo melanoma cells were spotted under vacuum onto Hybond-C super transfer nitrocellulose membrane by a 96-well dot blot apparatus and incubated for $1 \mathrm{~h}$ at RT. After three washings with PBS $/ 0.02 \%$ sodium azide, membranes were saturated with blocking buffer for $12 \mathrm{~h}$ at $4^{\circ} \mathrm{C}$, then incubated with $50 \mathrm{ml}$ blocking buffer containing $5 \times 10^{5} \mathrm{cpm} / \mathrm{ml}$ of ${ }^{125} \mathrm{I}-\mathrm{mAb}$ YTH53.1 for $2 \mathrm{~h}$ at RT. Before autoradiography, spot-bound radioactivity was measured by a MATRIX 96 Direct Beta Counter. (B) Melanoma cells $\left(10^{5}\right)$ were incubated sequentially with $10 \mu \mathrm{g} / \mathrm{ml}$ of antiCD59 mAb YTH53.1 and with DTAF-conjugated $\mathrm{F}\left(\mathrm{ab}^{\prime}\right)_{2}$ fragments of goat anti-rat IgG xenoantibodies; cells were then analyzed with flow cytometry. Levels of CD59, expressed as MESF values, were correlated by linear regression analysis with cpm values of spotbound ${ }^{125} \mathrm{I}-\mathrm{mAb}$ YTH53.1.

preincubated with undiluted and serial dilutions of CM; after a 15min incubation, $0.1 \mathrm{ml}$ of undiluted NHS was added in each well. After a 1-h incubation, supernatant $(0.1 \mathrm{ml})$ was harvested from each well and counted in a gamma counter. The percentage of cytotoxicity, the spontaneous release, and the total release were determined as described (11). Only experiments with a spontaneous/maximum release $<15 \%$ were used for data analysis.

Statistical analysis. Correlation analyses with a value of $r>0.7$, giving a value of $P<0.05$, obtained by using the least square linear regression, were considered statistically significant. Data analyzed by the Student's paired $t$ test with $P<0.05$ were considered statistically significant.

\section{Results}

Detection of sCD59 and cellular CD59 by dot blotting. To investigate whether melanoma cells may release a soluble form of CD59, serial dilutions of CM from melanoma cells expressing different levels of CD59 were tested in dot blot for the presence of sCD59. Fig. $1 A$ shows that CD59-positive Mel 97, Mel 90, Mel 116, Mel 134, Mel 100, Colo 38, and 70-W mela- 
noma cells shed detectable levels of sCD59 in their culture supernatants, while CD59-negative MeM 50-10 and MeWo melanoma cells did not. Levels of detected sCD59 decreased with serial dilutions of CM (Fig. $1 A$ ); moreover, a significant correlation between levels of sCD59 detectable in undiluted $(r=$ 0.926; $P<0.001$ ) (Fig. $1 B$ ), 1:10, and 1:100 dilutions of $\mathrm{CM}$ (data not shown) and corresponding cell surface expression of CD59 was found. Levels of cellular CD59 detected by dot blotting of cell lysates of Mel 97, Mel 90, Mel 116, Mel 134, Mel 100, Colo 38, MeM 50-10, and MeWo melanoma cells (Fig. 2 $A)$ significantly $(r=0.870, P<0.005)$ correlated with corresponding cell surface expression of CD59 (Fig. 2 B). sCD59 was detected in serial dilutions of CM from CD59-positive melanocytes and HUVEC but not from CD59-negative Nalm-6 pre-B cells (Fig. $3 A$ ). Fig. $3 B$ shows representative data demonstrating that sCD59 is also detectable in sera from healthy subjects, melanoma patients, and umbilical cord blood. Lastly, PI-PLC treatment of Mel 116 and Mel 97 melanoma cells released amounts of CD59 that were dependent on the dose of enzyme used (Fig. $3 C$ ).

Molecular profile of cellular CD59, sCD59, and AP sCD59, and insertion of AP sCD59 into homologous cell membranes. To analyze the molecular profile of sCD59 released by melanoma cells and to compare it with that of cellular CD59, CM, cell lysates, and AP sCD59 from CM of Mel 97 melanoma cells were immunoprecipitated by the anti-CD59 mAb MEM-43/5 and hybridized with ${ }^{125} \mathrm{I}$-anti-CD59 $\mathrm{mAb}$ YTH53.1. Fig. 4 shows that mAb YTH53.1 recognized multiple bands with apparent molecular masses from 16 to $21 \mathrm{kD}$ that were similar for sCD59 from CM (lane $A$ ), cellular CD59 (lane $B$ ), and AP sCD59 (lane $C$ ).

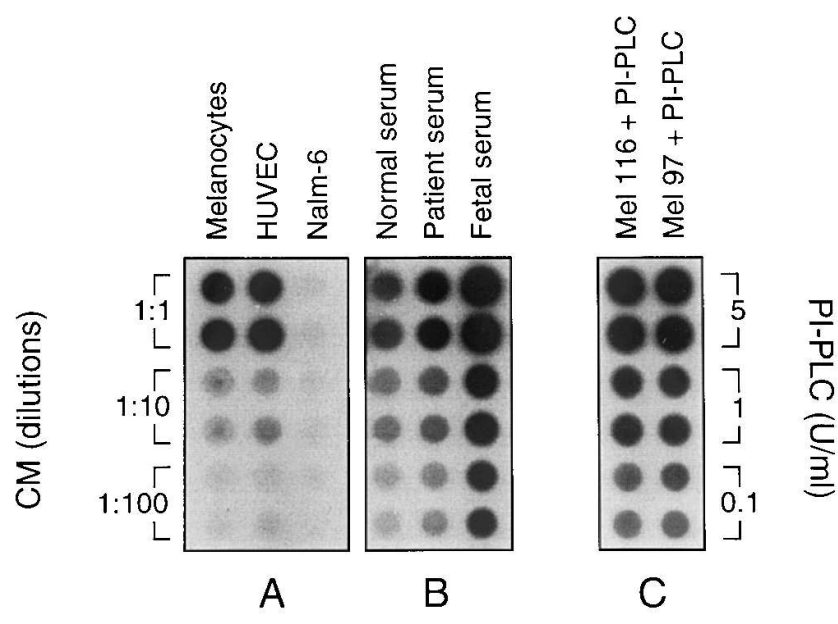

Figure 3. Dot blot analysis of sCD59 present in CM from nonmelanoma cells $(A)$, sera $(B)$, and supernatants of PI-PLC-treated melanoma cells $(C)$. (A) 50- $\mu$ l serial dilutions of $\mathrm{CM}$ from human melanocytes, HUVEC, and Nalm-6 cells; $(B) 50-\mu l$ serial dilutions of sera from a healthy subject, a patient with metastatic melanoma, and from umbilical cord vein; $(C)$ 20- $\mu$ l supernatants obtained after treatment of Mel 116 and Mel 97 melanoma cells with 5,1, and $0.1 \mathrm{U} / \mathrm{ml}$ of PIPLC were spotted under vacuum onto Hybond-C super transfer nitrocellulose membrane by a 96-well dot blot apparatus and incubated for $1 \mathrm{~h}$ at RT. After three washings with PBS/0.02\% sodium azide, membranes were saturated with blocking buffer for $12 \mathrm{~h}$ at $4^{\circ} \mathrm{C}$, then incubated with $50 \mathrm{ml}$ blocking buffer containing $5 \times 10^{5} \mathrm{cpm} / \mathrm{ml}{ }^{125} \mathrm{I}-$ $\mathrm{mAb}$ YTH53.1 for $2 \mathrm{~h}$ at RT. Membranes were then processed for autoradiography.

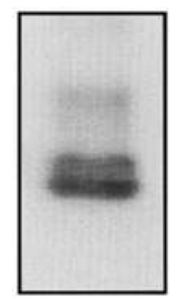

A

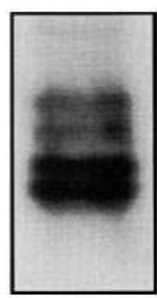

B

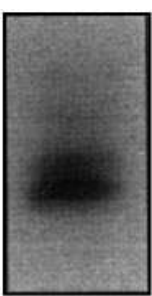

C
Figure 4. Molecular profile of cellular CD59, sCD59 from CM, and AP sCD59. Cell lysates $(200 \mu \mathrm{l})(A), \mathrm{CM}(2 \mathrm{ml})(B)$, and AP sCD59 $(15 \mu \mathrm{g})(C)$ from Mel 97 melanoma cells were immunoprecipitated by anti-CD59 mAb MEM-43/5, size-fractionated by a $15 \%$ one-dimensional SDS-PAGE under nonreducing conditions, blotted onto Hybond-C super transfer nitrocellulose membranes, and incubated with $50 \mathrm{ml}$ blocking buffer containing $5 \times 10^{5} \mathrm{cpm} / \mathrm{ml}{ }^{125} \mathrm{I}-\mathrm{mAb}$ YTH53.1 for $2 \mathrm{~h}$ at RT. Membranes were then processed for autoradiography.

To investigate the ability of sCD59 to insert into homologous cell membranes, the CD59-negative MeWo melanoma cells and the CD59-weakly positive 70-W melanoma cells were incubated for $2 \mathrm{~h}$ at $37^{\circ} \mathrm{C}$ with $\mathrm{AP}$ sCD59 from $\mathrm{CM}$ of Mel 97 melanoma cells and then analyzed by IIF for cell surface expression of CD59. Data representative of four independent experiments, performed with three different preparations of AP sCD59, are reported in Fig. 5, and show that AP sCD59 inserts into the cell membrane of both MeWo and 70-W melanoma cells. Values of mean fluorescence intensity obtained with the anti-CD59 mAb MEM-43/5 increased from 8 to 65 and from 38 to 121 for MeWo and 70-W melanoma cells, respectively, incubated in the absence or presence of AP sCD59. Insertion of AP sCD59 into the cell membrane of melanoma cells was dose dependent; in fact, incubation of melanoma cells with decreasing concentrations of AP sCD59 progressively reduced their staining with mAb MEM-43/5 (data not shown). To assess whether levels of cell membrane CD59 would remain stable after insertion of exogenous AP sCD59, one-half of the melanoma cell preparation analyzed in the experiment shown in Fig. 5 was washed, incubated for an additional $2 \mathrm{~h}$ at $37^{\circ} \mathrm{C}$ in the absence of AP sCD59, and analyzed by IIF for CD59 expression. Values of mean fluorescence intensity obtained with mAb MEM-43/5 decreased to 34 and 59, respectively, for MeWo and 70-W melanoma cells that had been preincubated with AP sCD59; in contrast, this additional incubation did not affect the constitutive expression of CD59 on control cells (data not shown).

Inhibition of the binding of mAb YTH53.1 to melanoma cells by sCD59. To investigate whether sCD59 released by melanoma cells retains the ability to be recognized by antiCD59 mAb and blocks their binding to cell membrane CD59, serial dilutions of CM from CD59-positive Mel 97 melanoma cells were preincubated with a fixed amount of ${ }^{125}$ I-labeled $\mathrm{mAb}$ YTH53.1; alternatively, undiluted CM was preincubated with serial dilutions of ${ }^{125}$ I-labeled mAb YTH53.1. Mixtures were then added to CD59-positive Mel 134 melanoma cells.

Fig. 6 shows data from a representative experiment out of three demonstrating that serial dilutions of CM from Mel 97 melanoma cells inhibited the binding of ${ }^{125} \mathrm{I}$-labeled $\mathrm{mAb}$ YTH53.1 to Mel 134 melanoma cells in a dose-dependent fash- 

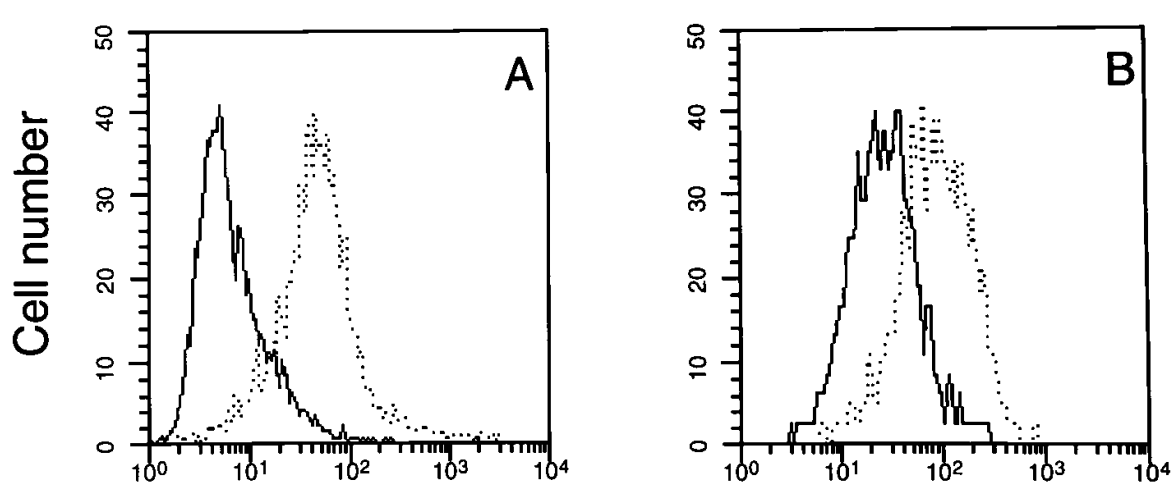

Fluorescence intensity
Figure 5. IIF analysis of AP sCD59 insertion into the cell membrane of melanoma cells. MeWo $(A)$ and 70-W $(B)$ melanoma cells were incubated with $(. .$.$) or with-$ out (- $5 \mu \mathrm{g} / \mathrm{ml} \mathrm{sCD} 59$ for $2 \mathrm{~h}$ at $37^{\circ} \mathrm{C}$. Cells were then washed, and cell surface expression of CD59 was detected by IIF followed by flow cytometry using the antiCD59 mAb MEM-43/5. ion. The inhibition was $>90 \%$ with dilutions of CM up to $1: 8$, and decreased thereafter. In contrast, no dilution of CM from CD59-negative MeWo melanoma cells and Nalm-6 pre-B cells affected the binding of ${ }^{125} \mathrm{I}$-labeled mAb YTH53.1 to Mel 134 melanoma cells (Fig. 6). Results similar to those obtained with CM from Mel 97 melanoma cells were obtained with CM from CD59-positive Mel 90 melanoma cells (data not shown).

The binding of serial dilutions of ${ }^{125}$ I-labeled mAb YTH53.1 to Mel 134 melanoma cells was also inhibited, in a dose-dependent fashion, by undiluted CM from Mel 97 melanoma cells but not from MeWo melanoma cells and Nalm-6 pre-B cells (data not shown).

Interference of sCD59 in the enhancement of C-lysis of melanoma cells mediated by the masking of cellular CD59 by $\mathrm{mAb}$ YTH53.1. Masking of CD59 by $2.5 \mu \mathrm{g} / \mathrm{ml}$ of mAb YTH53.1 enhanced C-mediated lysis of Mel 134 melanoma cells sensitized with $2.5 \mu \mathrm{g} / \mathrm{ml}$ of anti-GD3 mAb R24. Values of ${ }^{51} \mathrm{Cr}$ release increased from $23 \pm 5.6$ to $55.5 \pm 8.2 \%$ using NHS (1:2 final dilution) from three healthy donors as source of homologous C (data not shown). Therefore, the effect of CM from
Mel 97 melanoma cells, used as source of sCD59, on the increase of C-mediated lysis of Mel 134 melanoma cells induced by mAb YTH53.1 was investigated. Fig. 7 shows that serial dilutions of CM, preincubated with fixed amounts $(2.5 \mu \mathrm{g} / \mathrm{ml})$ of $\mathrm{mAb}$ YTH53.1 induced a dose-dependent inhibition of the increase of C-lysis of Mel 134 melanoma cells mediated by mAb YTH53.1. The percentage of inhibition was $86.8 \pm 11.4$ for undiluted CM, decreased thereafter, reached control values at 1:128 dilution of $\mathrm{CM}$, and was significantly $(P<0.05)$ different compared to CM from Nalm-6 pre-B cells up to a 1:64 dilution (Fig. 7). No inhibition of mAb YTH53.1 activity was observed using CM from Nalm-6 pre-B cells under similar experimental conditions (Fig. 7). Moreover, serial dilutions of CM from Mel 97 melanoma cells preincubated with mAb YTH53.1 did not affect C-mediated lysis of anti-GD3-sensitized CD59-negative MeWo melanoma cells (Fig. 7). The latter was also not enhanced by mAb YTH53.1 used alone (data not shown).

Consistent with the findings above, preincubation of scalar concentrations of mAb YTH53.1 with a fixed amount of CM from Mel 97 melanoma cells but not from Nalm-6 pre-B cells

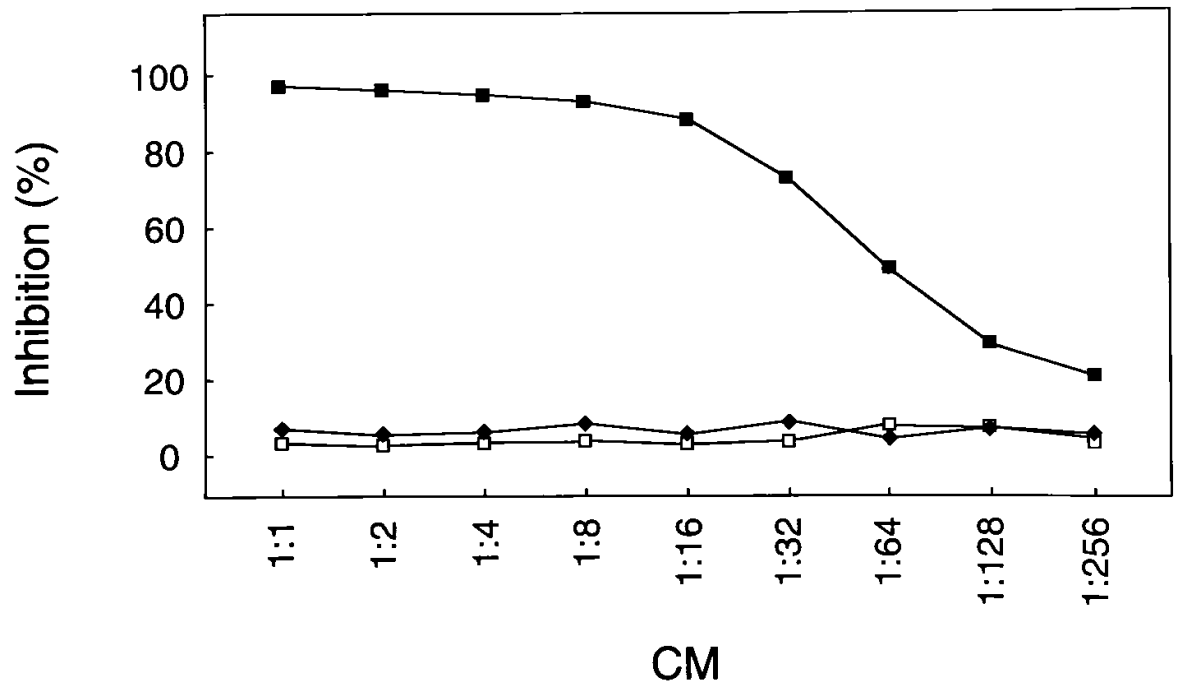

Figure 6. Effect of serial dilutions of CM from Mel 97 melanoma cells on the binding of ${ }^{125} \mathrm{I}$-labeled anti-CD59 $\mathrm{mAb}$ YTH53.1 to Mel 134 melanoma cells. Undiluted and twofold dilutions of CM $(0.8$ $\mathrm{ml}$ ) from CD59-positive Mel 97 melanoma cells (ם), CD59-negative MeWo melanoma cells $(\square)$, or Nalm-6 pre-B cells $(\bullet)$ were added with $7 \times 10^{5} \mathrm{cpm}^{125}$ I-labeled $\mathrm{mAb}$ YTH53.1 in $100 \mu \mathrm{l}$ PBS containing $1 \%$ nonfat dry milk and $0.02 \%$ sodium azide and incubated for $2 \mathrm{~h}$ at RT. Mel 134 melanoma cells $\left(5 \times 10^{5}\right)$ were then added, incubated for an additional $2 \mathrm{~h}$ at RT, washed four times with PBS containing 1\% nonfat dry milk and $0.02 \%$ sodium azide, and cell-bound radioactivity was counted in a gamma counter. $100 \%$ of binding of ${ }^{125}$ I-labeled mAb YTH53.1 to Mel 134 cells was assessed in the absence of CM. Data are expressed as percentage of inhibition by $\mathrm{CM}$ of the binding of ${ }^{125} \mathrm{I}$-labeled $\mathrm{mAb}$ YTH53.1 to melanoma cells. 


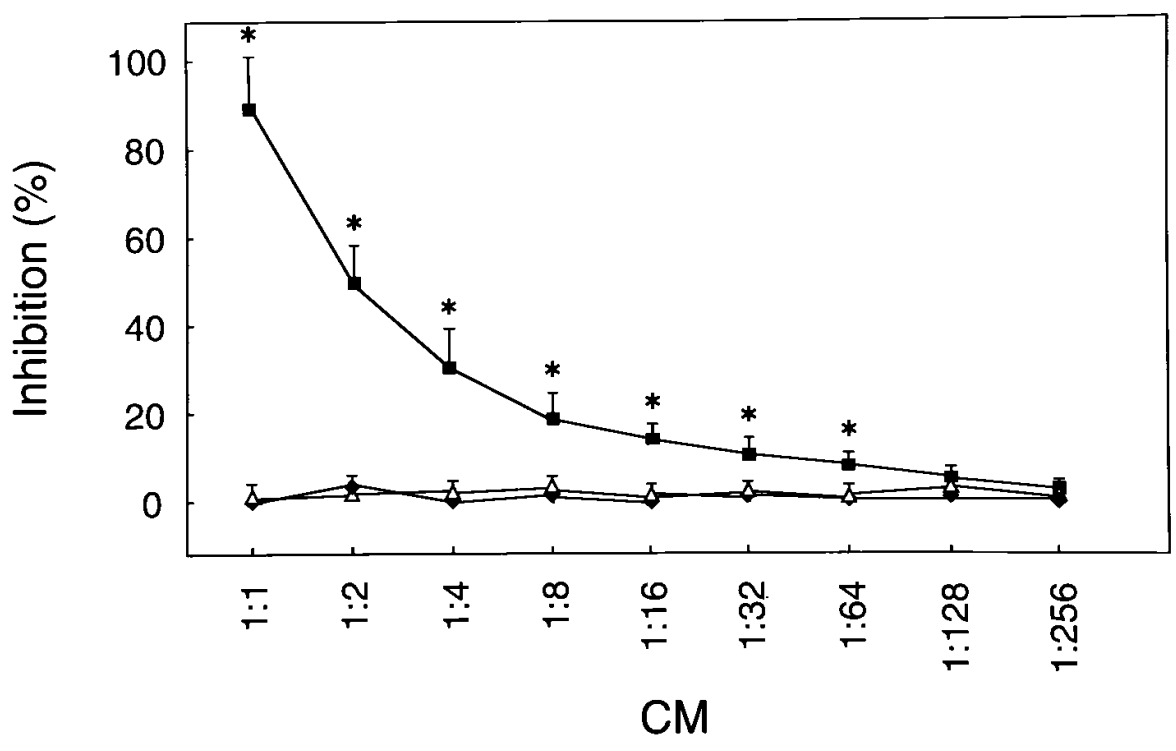

Figure 7. Effect of serial dilutions of CM from Mel 97 melanoma cells on the increase of C-mediated lysis induced by mAb YTH53.1. ${ }^{51} \mathrm{Cr}$-labeled Mel 134 melanoma cells were sensitized with $2.5 \mu \mathrm{g} / \mathrm{ml}$ of anti-GD3 mAb R24 and incubated with $2.5 \mu \mathrm{g} / \mathrm{ml}$ of anti-CD59 mAb YTH53.1 which had been preincubated for $2 \mathrm{~h}$ at RT with undiluted and twofold dilutions of CM from CD59-positive Mel 97 melanoma cells (ם) or CD59-negative pre-B Nalm-6 cells $(\bullet) .{ }^{51} \mathrm{Cr}$-labeled CD59-negative MeWo melanoma cells were incubated under the same experimental conditions with mAb YTH53.1 preincubated with CM from Mel 97 melanoma cells $(\triangle)$. After a 15-min incubation, cells were added with $100 \mu \mathrm{l}$ NHS from three healthy donors to a 1:2 final dilution. After a $1-\mathrm{h}$ incubation at $37^{\circ} \mathrm{C}$, plates were spun for $5 \mathrm{~min}$ at $30 \mathrm{~g}$; supernatant $(100 \mu \mathrm{l})$ was harvested from each well, and released radioactivity was

counted in a gamma counter. Results are expressed as percentage of inhibition by CM of the increase of C-mediated lysis induced by the combination of mAb R24 and mAb YTH53.1, compared to mAb R24 used alone. $* P<0.05$.

induced a dose-dependent inhibition of the increase of C-mediated lysis of Mel 134 melanoma cells mediated by mAb YTH53.1 (data not shown).

\section{Discussion}

The results presented in this study represent novel and unique findings demonstrating that melanoma cells constitutively release an anchor-positive sCD59, and that sCD59 is functional.

The intensity of the release of sCD59 by melanoma cells was found to be strictly dependent on the amounts of CD59 expressed on the cell membrane; consistent with this finding is the lack of detection of sCD59 and cellular CD59 in CM and cell lysates of CD59-negative MeM 50-10 and MeWo melanoma cells. In addition, Western blot analysis did not detect CD59 in the latter two cell lines while it did so in the additional melanoma cell lines investigated in this study (data not shown). The detection of sCD59 in CM from CD59-positive melanocytes demonstrates that the release of sCD59 is a common feature of melanocytic cells. Moreover, the release of sCD59 is likely to reflect a more general phenomenon for CD59-positive cells since HUVEC that express CD59 (11) but not CD59negative (data not shown) Nalm-6 pre-B cells release sCD59 in their culture supernatant. The identification of sCD59 in serum of healthy adults demonstrates that SCD59 is also present and detectable by immunoblotting in circulating blood, rather than being confined in sera from selected body areas such as retroplacental sera, or sera from umbilical cord blood (reference 16 and Fig. 3), or being detectable selectively in sera from children in the infancy period (16). In addition, the detection of sCD59 in serum of melanoma patients demonstrates that sCD59 is constitutively present in human sera under normal and neoplastic conditions. Further studies are necessary to investigate the potential correlation between levels of sCD59 detectable in serum of melanoma patients and the extent of disease; nevertheless, preliminary evidence suggests that levels of
sCD59 can be elevated in sera of patients affected by metastatic melanoma compared to healthy subjects (M. Maio, unpublished observation).

The components of sCD59 immunoprecipitated by $\mathrm{mAb}$ MEM-43/5 from CM of Mel 97 melanoma cells were similar to those of cellular CD59 immunoprecipitated from Mel 97 cell lysates, and to those of AP sCD59 derived from CM of Mel 97 melanoma cells. Consistent with these findings, Western blot analysis of unpurified sCD59 present in cell-free colostrum, milk, and seminal plasma revealed multiple bands with molecular masses ranging from 19 to $25 \mathrm{kD}$ (30). Accordingly, Western blot analysis revealed that SCD59 is released by human amniotic epithelial cells, and that multiple bands with molecular masses ranging from 18 to $23 \mathrm{kD}$ corresponded to sCD59 (14). The similarity of the molecular components identifying cellular CD59 and sCD59 strongly suggested the release of a structurally intact and potentially functional form of CD59 by melanoma cells. To test these hypotheses, we investigated whether sCD59 released by melanoma cells inserts into homologous cell membranes, and whether it inhibits the binding and the functional effects of anti-CD59 mAb on C-mediated lysis of melanoma cells.

Insertion experiments demonstrated that sCD59 released by melanoma cells is anchor positive and retains the ability to incorporate into the cell membranes of allogeneic melanoma cells. The release of an anchor-positive sCD59 is further supported by the reduction of AP sCD59 insertion into cell membranes of 70-W melanoma cells when the assay was performed in the continuous presence of $30 \%$ NHS (data not shown). In fact, it has been reported recently that anchor-positive CD59 extracted from human erythrocytes, but not anchor-negative sCD59 purified from urine, partially incorporates into highdensity lipoprotein from human plasma that can physiologically act as a carrier of anchor-positive CD59 in human plasma (31). The increase in the constitutive levels of cellular CD59 obtained after insertion of exogenous sCD59 into cell mem- 
branes was transient, demonstrating a rapid release of inserted sCD59 and/or endogenous cellular CD59 from the cell membrane. Consistent with our finding, half of the human erythrocyte-derived CD59 inserted in vitro into U937 cells was lost after a 2-h incubation in the absence of exogenous CD59 (32). Altogether, this in vitro evidence may imply that in vivo CD59 expressed by melanoma cells at tumor sites constitutively undergoes a process of release that can be followed by its reinsertion into the cell surface and by its entry into the blood stream. The rapid decrease in the levels of cellular CD59 after insertion of AP sCD59 may explain the observed lack of significant protection of MeWo and 70-W melanoma cells from C-mediated lysis (data not shown). However, the absolute increase in the level of cellular CD59 that we obtained in vitro was limited, suggesting that levels of cellular CD59 required to confer protection from C-mediated lysis to investigated melanoma cells may not have been reached. This explanation is supported by our previous findings demonstrating that low levels of cell surface CD59 confer either limited or no protection from C-mediated lysis to neoplastic cells of the melanocytic lineage (12). To provide additional experimental support for this assumption, we are currently trying to generate high levels of cell membrane CD59 by CD59 gene transfer into melanoma cells.

The results from our insertion studies represent, to the best of our knowledge, unique direct evidence demonstrating that released sCD59 is able to insert transiently into the cell membrane of homologous cells, and that insertion into the cell membrane occurs regardless of the constitutive expression of cellular CD59 by target cells. In fact, previous studies have shown that sCD59 purified from human amniotic fluid (14) and seminal plasma $(15,33)$ efficiently inserts into CD59-positive heterologous cells, mainly represented by guinea pig erythrocytes.

The release of a functional form of sCD59 by melanoma cells was confirmed by the demonstration that CM from CD59-positive Mel 97 melanoma cells inhibits the binding of anti-CD59 mAb YTH53.1 to CD59-positive Mel 134 melanoma cells. The functional activity of sCD59 released by melanoma cells was further supported by the demonstration that it reverses the increase of homologous $\mathrm{C}$-mediated cytotoxicity of anti-GD3-sensitized Mel 134 melanoma cells, mediated by the masking of cell membrane CD59 by mAb YTH53.1. These data are highly relevant in view of the recently suggested possibility of using mAb YTH53.1 for immunotherapy in melanoma patients. In fact, biotinylated mAb YTH53.1 retains its ability to enhance C-mediated lysis of anti-GD3-sensitized melanoma cells while it loses its capacity to activate C-cascade and, thus, to induce nonspecific C-mediated lysis of CD59-positive, bystander nonneoplastic cells (13). In this scenario, in addition to the acknowledged difficulties of mAb to efficiently penetrate into neoplastic tissues of solid malignancies (34), the release of sCD59 by melanoma cells in the tumor microenvironment would highly impair the ability of anti-CD59 mAb to target CD59 expressed on the cell surface of melanoma cells and, thus, to enhance their destruction by autologous C. Moreover, it has been suggested that constitutive levels of sCD59 generated by different cell types and detectable in different human body fluids provide an additional physiological mechanism of cellular protection from C-lytic activity under inflammatory or infectious conditions $(15,30,33)$. Consistent with this idea, the release of an anchor-positive sCD59 by mela- noma cells may represent a mechanism for protecting neoplastic cells from C-mediated lysis within the tumor microenvironment.

The detection of a soluble form of CD59 released by neoplastic cells of melanocytic origin adds to the complexity of immunotherapeutic approaches for the treatment of human melanoma $(24,35)$. Nevertheless, the ability of CD59 to regulate $\mathrm{C}$-sensitivity of neoplastic cells is of great biological and of potential therapeutic relevance: the availability of technologies that can modulate gene expression both in vitro and in vivo may help future studies designed to downregulate CD59 expression and the consequent release of sCD59 by neoplastic cells and, eventually, to modulate their susceptibility to constitutive and/or treatment-induced humoral immune response.

\section{Acknowledgments}

This work was supported in part by the Associazione Italiana per la Ricerca sul Cancro, by the Progetto Ricerca Finalizzata awarded by the Italian Ministry of Public Health, and by the ISS-Programma Cooperativo Italo-Americano per la Terapia dei Tumori. L.I. Brasoveanu is a visiting fellow from the Institute of Oncology of Bucharest, Romania.

\section{References}

1. Morgan, B.P., and S. Meri. 1994. Membrane proteins that protect against complement lysis. Springer Semin. Immunopathol. 15:369-396.

2. Davies, A., and P.J. Lachmann. 1993. Membrane defence against complement lysis: the structure and biological properties of CD59. Immunol. Res. 12: 258-275.

3. Lehto, T., and S. Meri. 1993. Interactions of soluble CD59 with the terminal complement complexes. J. Immunol. 151:4941-4949.

4. Davies, A., D.L. Simmons, G. Hale, R.A. Harrison, H. Tighe, P.J. Lachmann, and H. Waldmann. 1989. CD59, an LY-6-like protein expressed in human lymphoid cells, regulates the action of the complement membrane attack complex on homologous cells. J. Exp. Med. 170:637-654.

5. Meri, S., H. Waldmann, and P.J. Lachmann. 1991. Distribution of protectin (CD59), a complement membrane attack inhibitor, in normal human tissues. Lab. Invest. 65:532-536.

6. Telen, M.J., and W.F. Rosse. 1991. Phosphatidylinositol-glycan linked proteins of the erythrocyte membrane. Baillière's Clinical Haematology. 4:849-868.

7. Mäenpää A., S. Junnikkala, J. Hakulinen, T. Timonen, and S. Meri. 1996. Expression of complement membrane regulators membrane cofactor protein (CD46), decay accelerating factor (CD55), and protectin (CD59) in human malignant gliomas. Am. J. Pathol. 148:1139-1152.

8. Hakulinen, J., and S. Meri. 1994. Expression and function of the complement membrane attack complex inhibitor protectin (CD59) on human breast cancer cells. Lab. Invest. 71:820-827.

9. Bjørge, L., C.A. Vedeler, E. Ulvestad, and R. Matre. 1994. Expression and function of CD59 on colonic adenocarcinoma cells. Eur. J. Immunol. 24: 1597-1603.

10. Niehans, G.A., D.L. Cherwitz, N.A. Staley, D.J. Knapp, and A.P. Dalmasso. 1996. Human carcinomas variably express the complement inhibitory proteins CD46 (membrane cofactor protein), CD55 (decay-accelerating factor), and CD59 (protectin). Am. J. Pathol. 149:129-142.

11. Brasoveanu, L.I., M. Altomonte, A. Gloghini, E. Fonsatti, S. Coral, A. Gasparollo, R. Montagner, I. Cattarossi, C. Simonelli, A. Cattelan, et al. 1995. Expression of protectin (CD59) in human melanoma and its functional role in cell- and complement-mediated cytotoxicity. Int. J. Cancer. 61:548-556.

12. Brasoveanu, L.I., M. Altomonte, E. Fonsatti, F. Colizzi, S. Coral, M.R. Nicotra, I. Cattarossi, A. Cattelan, P.G. Natali, and M. Maio. 1996. Levels of cell membrane CD59 regulate the extent of complement-mediated lysis of human melanoma cells. Lab. Invest. 74:33-42.

13. Junnikkala, S., J. Hakulinen, and S. Meri. 1994. Targeted neutralization of the complement membrane attack complex inhibitor CD59 on the surface of human melanoma cells. Eur. J. Immunol. 24:611-615.

14. Rooney, I.A., and B.P. Morgan. 1992. Characterization of the membrane attack complex inhibitory protein CD59 antigen on human amniotic cells and in amniotic fluid. Immunology. 76:541-547.

15. Rooney, I.A., J.P. Atkinson, E.S. Krul, G. Schonfeld, K. Polakoski, J.E. Saffitz, and B.P. Morgan. 1993. Physiologic relevance of the membrane attack complex inhibitory protein CD59 in human seminal plasma: CD59 is present on extracellular organelles (prostasomes), binds cell membranes, and inhibits com- 
plement-mediated lysis. J. Exp. Med. 177:1409-1420.

16. Bjørge, L., T.S. Jensen, C.A. Vedeler, E. Ulvestad, E.K. Kristoffersen, and R. Matre. 1993. Soluble CD59 in pregnancy and infancy. Immunol. Lett. 36: 233-234.

17. Roddy, J., I. Clark, B.L. Hazleman, D.A.S. Compston, and N.J. Scolding. 1994. Cerebrospinal fluid concentrations of the complement MAC inhibitor CD59 in multiple sclerosis and patients with other neurological disorders. $J$. Neurol. 241:557-560.

18. Altomonte, M., F. Colizzi, G. Esposito, and M. Maio. 1992. Circulating intercellular adhesion molecule 1 as a marker of disease progression in cutaneous melanoma. N. Engl. J. Med. 327:959.

19. Maio, M., B. Gulwani, J.A. Langer, R.S. Kerbel, G.J. Duigou, P.B. Fisher, and S. Ferrone. 1989. Modulation by interferons of HLA antigen, highmolecular-weight melanoma-associated antigen, and intercellular adhesion molecule 1 expression by cultured melanoma cells with different metastatic potential. Cancer Res. 49:2980-2987.

20. Bernhard, H., K. Meyer zum Bhshenfelde, and W.G. Dippold. 1989. Gangliosides GD3 shedding by human malignant melanoma cells. Int. J. Cancer. 44:155-160.

21. Altomonte, M., A. Gloghini, G. Bertola, A. Gasparollo, A. Carbone, S. Ferrone, and M. Maio. 1993. Differential expression of cell adhesion molecules CD54/CD11a and CD58/CD2 by human melanoma cells and functional role in their interaction with cytotoxic cells. Cancer Res. 53:3343-3348.

22. Becker, J.C., C. Termeer, R.E. Schmidt, and E.B. Bröcker. 1993. Soluble intercellular adhesion molecule-1 inhibits MHC-restricted specific T cell/tumor interaction. J. Immunol. 151:7224-7232.

23. Puppo, F., M. Scudeletti, F. Indiveri, and S. Ferrone. 1995. Serum HLA class I antigens: markers and modulators of an immune response? Immunol. Today. 16:124-127.

24. Maio, M., and G. Parmiani. 1996. Melanoma immunotherapy: new dreams or solid hopes? Immunol. Today. 17:405-407.

25. Stefanova, I., I. Hilgert, H. Kristofova, R. Brown, M.G. Low, and V. Horejsi. 1989. Characterization of a broadly expressed human leucocyte surface antigen MEM-43 anchored in membrane through phosphatidylinositol. Mol.
Immunol. 26:153-161.

26. Houghton, A.N., D. Mintzer, C. Cordon-Cardo, S. Welt, B. Fliegel, S Vadhan, E. Carswell, M.R. Melamed, H.F. Oettgen, and L.J. Old. 1985. Mouse monoclonal IgG3 antibody detecting GD3 ganglioside: a phase I trial in patients with malignant melanoma. Proc. Natl. Acad. Sci. USA. 82:1242-1246.

27. Maio, M., M. Altomonte, R. Tatake, R.A. Zeff, and S. Ferrone. 1991. Reduction in susceptibility to natural killer cell-mediated lysis of human F0-1 melanoma cells after induction of HLA-class-I antigen expression by transfection with B2m gene. J. Clin. Invest. 88:282-289.

28. Laemmli, U.K. 1970. Cleavage of structural proteins during the assembly of the head of bacteriophage $\mathrm{T}_{4}$. Nature (Lond.). 227:680-685.

29. Rodeck, U., A. Bossler, U. Graeven, F.E. Fox, P.C. Nowell, C. Knabbe, and C. Kari. 1994. Transforming growth factor $\beta$ production and responsiveness in normal human melanocytes and melanoma cells. Cancer Res. 54:575-581.

30. Bjørge, L., T.S. Jensen, E.K. Kristoffersen, M. Ulstein, and R. Matre. 1996. Identification of the complement regulatory protein CD59 in human colostrum and milk. Am. J. Reprod. Immunol. 35:43-50.

31. Väkevä, A., M. Jauhiainen, C. Ehnholm, T. Leto, and S. Meri. 1994 High-density lipoproteins can act as carriers of glycophosphoinositol lipidanchored CD59 in human plasma. Immunology. 82:28-33.

32. van den Berg, C.W., T. Cinek, M.B. Hallett, V. Horejsi, and P. Morgan. 1995. Exogenous glycosyl phosphatidylinositol-anchored CD59 associates with kinase in membrane clusters on U937 cells and became $\mathrm{Ca}^{2+}$-signaling competent. J. Cell Biol. 131:669-677.

33. Rooney, I.A., J.E. Heuser, and J.P. Atkinson. 1996. GPI anchored complement regulatory proteins in seminal plasma. J. Clin. Invest. 97:1675-1686.

34. Riethmüller, G., E. Schneider-Gädicke, and J.P. Johnson. 1993. Monoclonal antibodies in cancer therapy. Curr. Opin. Immunol. 5:732-739.

35. Brasoveanu, L.I., M. Altomonte, E. Fonsatti, S. Coral, A. Visintin, A. Cattelan, P.G. Natali, and M. Maio. 1996. Role of protectin (CD59) as regulator of complement-mediated lysis of melanoma cells: relevance in immunotherapy. In Immunology of Human Melanoma. Tumor-Host Interaction and Immunotherapy. M. Maio, editor. IOS Press, Ohmsa/Amsterdam/Tokyo/Washington, D.C. $185-194$ 